\title{
Surdocegueira, comunicação e alfabetização: um mapeamento de estudos
}

\section{Deafblindness, communication and literacy: a mapping of studies}

\begin{abstract}
ALVARISTO, Eliziane de Fátima ${ }^{1}$
SANTINELLO, Jamile ${ }^{2}$

HALLAL, Renato 3

Resumo

Este estudo objetiva investigar o que apresentam os estudos sobre comunicação e alfabetização de estudantes com surdocegueira na perspectiva da educação inclusiva. Para tanto, realizou-se um mapeamento de estudos no período de 2008 a 2020 na base de dados do Portal de Periódicos CAPES/MEC/BRASIL. Os resultados apresentam estudos que discutem sobre formas para a comunicação, entretanto, ausências no processo da alfabetização de estudantes com surdocegueira. Contudo, o cenário educacional carece de estudos, a abordar práticas pedagógicas que incitem tal processo.
\end{abstract}

Palavras-chave: surdocegueira; comunicação e alfabetização; educação inclusiva.

\begin{abstract}
This study aims to investigate what the studies on communication and literacy of students with deafblindness present in the perspective of inclusive education. To this end, a mapping of studies was carried out in the period from 2008 to 2020 in the database of the Portal of Periodicals CAPES/MEC/BRASIL. The results present studies that discuss ways to communicate, however, absences in the process of literacy of students with deafblindness. However, the educational scenario lakcs studies adressing pedagogical practices that encourage such a process.

Keywords: deafblindness; communication and literacy; inclusive education.
\end{abstract}

\section{Introdução}

A partir da política brasileira de inclusão as escolas têm recebido um crescente número de estudantes com deficiência nas redes regulares de ensino, com surdocegueira, deficiência visual, deficiência intelectual, transtorno global do desenvolvimento, altas habilidades/superdotação, dentre outras deficiencias e/ou transtornos (Brasil, 2015; Brasil, 2008; Brasil, 1996).

Este estudo trata-se específicamente da surdocegueira, a considerar uma deficiência que apresenta perdas visuais e auditivas que podem ocorrer concomitantemente, sendo congênitas ou adquiridas, podendo ser total ou parcial e leva a pessoa com essa deficiência a buscar novas formas de comunicação. Desse modo, é importante

\footnotetext{
${ }^{1}$ Doutoranda em Educação pela Universidade Estadual do Centro-Oeste (UNICENTRO). Brasil. lizi1984professora@gmail.com.

2 Doutora em Comunicação. Docente na Universidade Universidade Estadual do Centro-Oeste (UNICENTRO) Brasil. jamile@unicentro.br.

${ }_{3}$ Doutorando em Ensino de Ciência e Tecnologia pela Universidade Tecnológica Federal do Paraná (UTFPR/PG). Docente na Universidade Tecnológica Federal do Paraná (UTFPR). Brasil. renatohallal@utfpr.edu.br.
} 
esclarecer que, quando a visão e a audição estão muito comprometidas, os problemas relacionados a aprendizagem se multiplicam devido a falta dessas percepções. Assim sendo, é importante compreender sobre a surdocegueira, pois quando faltam os sentidos remanescentes (audição e visão), o tato assume o papel de sentido-guia, sendo complementado por outros sentidos, a considerar novas formas na exploração e no estabelecimento de contatos com o mundo exterior (Brasil, 2006).

Consideram-se importantes algumas características em estudantes com surdocegueira, tais como: i) dificuldades em elaborar a consciência da relação corporal; ii) limitações para o movimento e funcionamento do próprio corpo; iii) insegurança pessoal; iv) atraso no desenvolvimento motor e afetivo, por isso a importância de profissionais habilitados na área, a estimular o desenvolvimento global de modo organizado e coeso com a necessidade de cada estudante, a considerar que podem apresentar características distintas em função de vários aspectos, sendo grau de perda auditiva, grau de perda visual, características de interação com o meio, comprometimentos associados a deficência surdocegueira, como motor e neurológica e também a relação com o meio emocional, cultural e social implicam neste processo (Brasil, 2006).

À vista disso, é importante que profissionais da educação compreendam sobre a necessidade de desenvolver novas formas e metodologias para a comunicação com estudantes surdocegos. Isso remete a novos desafios enfrentados por profissionais envolvidos com área da educação especial e da educação inclusiva.

Na perspectiva de apresentar meios para o processo de aprendizagem, Vygotsky $(1991 ; 1997)$ evidenciou que, são necessários estímulos que proporcionem à singularidade de cada pessoa para suprir suas necesidades, a considerar a linguagem essencial para a aprendizagem. Nesse sentido, é importante conhecer qual é o meio de comunicação, recurso didático ou tecnológico para a comunicação com estudantes surdocegos, a objetivar formas adequadas a serem estabelecidas na interelação entre professores e estudantes.

Estudos apontam (Araújo et al., 2019; Branco; Leal, 2018; Giacomini; Maia, 2005; Costa; Cader-Nascimento, 2003) sobre a importância da realização de novas pesquisas para a área da surdocegueira, relativa a metodologias e formas comunicacionais, a orientar professores e estudantes surdocegos à comunicação, a amenizar e até mesmo eliminar lacunas que inferem no processo de aprendizagem destes estudantes, muitas vezes pela ausência de comunicação. Haja vista tal necessidade, é importante clarificar que a educação é um direito de todo cidadão já proclamado na Declaração Universal dos Direitos Humanos (1948) ${ }^{4}$. Portanto, é importante repensar sobre a educação e o processo de aprendizagem como algo muito peculiar de cada ser humano.

O processo de alfabetização é considerado algo gradativo que envolve ensinar a ler e a escrever, e aos poucos a compreensão e aquisição da leitura e da escrita. O letramento revela o contexto social relacionado com as práticas para a alfabetização. Essas práticas estão associadas com a ação pedagógica que possibilita aos estudantes a apropriação da alfabetização e do letramento, pois o ideal é alfabetizar letrando (Soares, 1998). Dessa forma, a importância das práticas pedagógicas no processo da alfabetização e do letramento na idade certa visa à apropriação da escrita e da leitura, a partir do Pacto Nacional pela Alfabetização na Idade Certa (PNAIC), o qual foi estabelecido pela portaria no 867, de 4 de julho de 2012, definindo assim as ações e diretrizes para o Programa, a objetivar a formação continuada de professores alfabetizadores (Brasil, 2012).

Frangella (2016) têm discutido sobre as políticas do PNAIC, o qual tem como intuito criar estratégias para que todas as crianças estejam alfabetizadas até o final do $3^{\circ}$ ano do ensino fundamental, porém, vale salientar que

${ }^{4}$ Disponível em: <https://nacoesunidas.org/wp-content/uploads/2018/10/DUDH.pdf>. Acesso em: 10 ago. 2020. 
devemos respeitar o processo de desenvolvimento de cada pessoa e a forma como ela se desenvolve, a considerar as pessoas com surdocegueira.

Cruz e Martiniak (2018) evidenciam em seus estudos sobre o PNAIC que, apesar de várias pesquisas tratarem sobre a temática da alfabetização voltada para o ensino da leitura e da relação com a formação dos alfabetizadores, ainda apresentam-se carências de estudos voltados para a alfabetização na área da inclusão, a considerar que, se a educação é para todos, devemos conceder a qualidade para o ensino, em que é imprescindível a troca de conhecimentos divulgados a partir de estudos científicos.

Nesse víes, a tratar especificamente na área da comunicação e alfabetização de estudantes com surdocegueira, levantou-se a seguinte reflexão, no intento de entender como estudantes com surdocegueira se comunicam e se alfabetizam, de modo a produzirem diálogos. Para Bakthin (1997) o diálogo é algo que necessita do outro para produzir sentido, formas de compreender a experiência humana a partir da linguagem. Para as pessoas com surdocegueira não é diferente, porém, necessitam fazer uso da linguagem de maneira diferenciada para dialogar/comunicar, a partir de outros métodos, como, por exemplo,o tadoma (pouco usado pela complexidade de ensino e aprendizagem), intérpretes e língua de sinais, braille, alfabeto dacticológico, tablitas de comunicação, letras de forma, dentre outros (Almeida, 2017; Souza; Filho, 2017, Gomes; Nunes, 2013).

Na perspectiva da educação inclusiva, pretende-se neste estudo investigar o que apresentam os estudos sobre comunicação e alfabetização de estudantes com surdocegueira. De modo a ampliar as concepções de pesquisadores, professores e estudantes que buscam ressignifcar sentidos voltados para a comunicação e alfabetização na educação de estudantes com surdocegueira.

\section{Metodologia}

Este estudo decorre de um mapeamento de estudos sobre a comunicação e a alfabetização de estudantes com surdocegueira na perspectiva da educação inclusiva. Utilizou-se a base de dados do Portal de Periódicos CAPES/MEC/BRASIL, a constatar dados entre o período de 2008 a 2020.

Os procedimentos adotados para o mapeamento de pesquisas foram fundamentados a partir de Sampaio e Mancini (2007), como mostra a Figura 1.

Para análise e discussão de dados discorre-se sobre os objetivos e metodologias aplicadas nos estudos, a considerar:

i. Abordagem

ii. Estratégia

iii. Ambiente e Participantes

iv. Instrumentos adotados para a análise dos dados sobre comunicação e alfabetização de estudantes com surdocegueira na perspectiva da Educação Inclusiva.

A análise e a discussão dos dados foram fundamentas a partir da abordagem qualitativa (Flick, 2009). 
Figura 1

Fluxograma da organização dos

procedimentos adotados no estudo

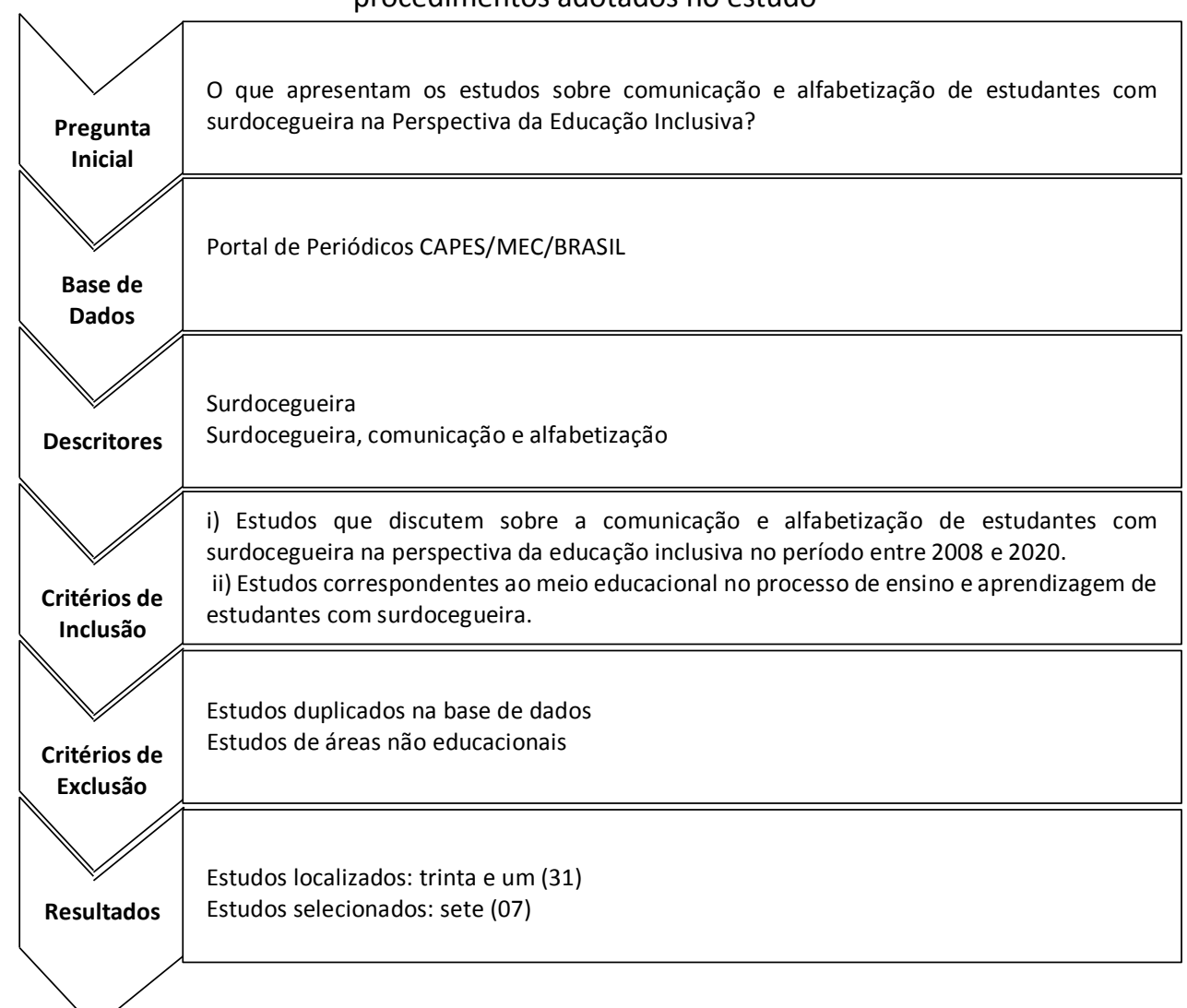

Fonte: elaboração dos autores a partir de (Sampaio; Mancini, 2007).

\section{Resultados e discussão}

Frente aos procedimentos adotados para a aplicação dos critérios de inclusão e exclusão, foram localizados trinta e um (31) estudos na base do Portal de Periódicos CAPES/MEC/Brasil, sendo vinte e oito (28) com o descritor 'surdocegueira' e três com os descritores 'surdocegueira, comunicação e alfabetização'. Destes foram selecionados sete (7) estudos para a análise e discussão. O mapeamento dos estudos são apresentados no Quadro 1.

\section{Quadro 1}

Estudos selecionados para análise dos dados

\begin{tabular}{|c|l|}
\hline $\mathbf{N}^{\circ}$ & \multicolumn{1}{c|}{ REFERÊNCIAS } \\
\hline \multirow{2}{*}{1} & $\begin{array}{l}\text { Almeida, W. G. A guia-interpretação no processo de inclusão do individuo com surdocegueira. Educar em } \\
\text { Revista, n. 65, p. 167-181, jul./set. 2017. Disponível em: } \\
\text { <https://revistas.ufpr.br/educar/article/view/49000>. Acesso em 08 fev. 2020. }\end{array}$ \\
\hline 2 & $\begin{array}{l}\text { Andrade, A. F. Surdocegueira, Cartografia e Decolonialidade. Psicologia: Ciência e Profissão, v. 38, n. 3, p. } \\
595-610, \text { jul./Set. 2018. Disponível em: <https://dialnet.unirioja.es/servlet/articulo?codigo=6594582>. } \\
\text { Acesso em: 10 fev. 2020. }\end{array}$ \\
\hline 3 & $\begin{array}{l}\text { Araújo et al. Os padrões de comunicação da surdocegueira nos contextos familiar e educacional. Revista } \\
\text { Educação Especial, v. 32, p. 1-19. 2019. <https://periodicos.ufsm.br/educacaoespecial/article/view/30185. } \\
\text { Acesso em: 18 mar. 2020. }\end{array}$ \\
\hline \multirow{3}{*}{3} & $\begin{array}{l}\text { Bigate, F. T; Lima, W. R. N. Práticas Pedagógicas no Proceso de Reabilitação de alunos com Surdocegueira. } \\
\text { Revista Educação Especial, v. 32, p. 1-23. 2019. Disponível em: < } \\
\text { https://periodicos.ufsm.br/educacaoespecial/article/view/34756/34756>. Acesso em: } 20 \text { jun. 2020. }\end{array}$ \\
\hline
\end{tabular}




\begin{tabular}{|c|l|}
\hline 5 & $\begin{array}{l}\text { Branco, C. S. P. A; Leal, D. Inclusão de alunos surdocegos e a atuação de professores no ensino comum: } \\
\text { revisão sistemática. Revista Educação Especial, v. 31, n. 61, p. 323-338, abr/jun. 2018. Disponível em: } \\
\text { <https://periodicos.ufsm.br/educacaoespecial/article/view/26295/pdf>. Acesso em: 04 mar. 2019. }\end{array}$ \\
\hline 6 & $\begin{array}{l}\text { Figueiredo, A. Z. M; Chiari, B. M; Goulart, G. N. B. Comunicação em adultos surdocegos com síndrome de } \\
\text { Usher: estudo observacional retrospectivo. Revista Codas, v. 25, n. 4, p. 319-324. 2013.Disponível em: } \\
\text { https://www.scielo.br/scielo.php?pid=S2317-17822013000400004\&script=sci_abstract\&tlng=pt>. Acesso } \\
\text { em: } 10 \text { maio. 2020. }\end{array}$ \\
\hline \multirow{7}{*}{7} & $\begin{array}{l}\text { Galvão, S. S. C. N; Miranda, G. T. Atendimento educacional especializado para alunos com surdocegueira: } \\
\text { um estudo de caso no espaço da escola regular. Rev. Bras. Ed. Esp., Marília, v. 19, n.1, p. 43-60, Jan.- Mar. } \\
\text { 2013. Disponível em: < } \\
\text { https://www.researchgate.net/publication/291053330_Atendimento_educacional_especializado_para_alu } \\
\text { nos_com_surdocegueira_um_estudo_de_caso_no_espaco_da_escola_regular >. Acesso em: 18 fev. 2020. }\end{array}$ \\
\hline
\end{tabular}
Fonte: elaboração dos autores (2021)

Alguns estudos (Watanabe; Maia, 2012; Wanatabe; Brasil, 2006; Giacomini; Maia, 2006) apresentam sobre várias posibilidades para a comunicação e alfabetização à pessoas com surdocegueira, tais como: língua de sinais tátil; braille tátil; alfabeto datilológico ou alfabeto manual tátil; fala ampliada; escrita do alfabeto/palavras de uma língua oral escrita com um dos dedos da mão numa parte sensível do corpo; escrita ampliada; língua de sinais aérea em campo reduzido; tadoma; placas alfabéticas com letras e números em relevo; placas alfabéticas em Braille. Estes recursos possibilitam a comunicação e a alfabetização de estudantes com surdocegueira, no entanto, devem estar associados com a qualificação dos profissionais da educação, no sentido de saber fazer uso, para melhorar a qualidade no ensino e na comunicação destes estudantes

Haja vista a importância da comunicação para pessoas com surdocegueira, Araújo et al. (2019), buscou compreender os padrões de comunicação de duas jovens surdocegas no contexto familiar e escolar, a analizar a possibilidade de desenvolvimento de uma linguagem simbólica no processo de interação com esses ambientes. O estudo teve como participantes duas jovens surdocegas, suas genitoras e suas professoras/guias intérpretes. A aplicação do estudo foi realizada em centros de formação de psicologia aplicada, localizados em Brasília e em Planaltina, ambos no Distrito Federal e, também na residência de uma das participantes, devido a fragilidades deferidas em seu estado emocional. Os instrumentos utilizados foram entrevistas e questionário socidemográfico. Os dados foram analisados e discutidos a partir da teoria de análise de conteúdo de Bardin.

Os resultados revelam que os padrões de comunicação na familia, necessitam de interverções de intérpretes e do uso de tecnologias acessíveis. E os padrões de comunicação na escola mais utilizado pelas participantes foi a Língua Brasileira de Sinais (Libras), a considerar a baixa visão a nível surdocegueira. Todavia, é importante ressalvar que, segundo Araújo et al. (2019), há também, outras formas para comunicação e até mesmo para a alfabetização de estudantes com surdocegueira, a considerar a importância de práticas e metodologias aplicadas, bem como, a atuação do guía-intérprete.

Aproximando-se do viés abordado por Araújo et al. (2019), sobre a importância da comunicação para estudantes com surdocegueira, Almeida (2017) buscou investigar a atuação do profissional guia-intérprete no atendimento a estes estudantes, a identificar os procedimentos de intervenção utilizados pelos profissionais, a partir de práticas comunicativas com surdocegos. $\mathrm{O}$ estudo foi realizado em instituições de ensino da rede pública e privada e também em associações de atendimento às pessoas com surdocegueira. Os participantes foram onze guias-interpretes. Almeida (2017) traz como estratégia metodológica, o estudo de caso descritivo. Os instrumentos de investigação foram entrevista e observação direta.

Os resultados mostram que a falta de informações e de conhecimentos específicos sobre a deficiência surdocegueira foi um fator determinante para o surgimento de barreiras, a atingir tanto a qualidade dos serviços prestados ao surdocego quanto a realidade social deste indivíduo. Desse modo, o estudo aponta para a 
necessidade de formação e capacitação inicial e continuada tanto do profissional guia-intérprete quanto do professor especialista e do professor do ensino regular para melhor comunicação com as pessoas surdocegas.

Concomitantemente ao estudo abordado por Almeida (2017), Bigatte e Lima (2019) analisaram as práticas pedagógicas empregadas no processo de reabilitação de alunos com surdogueira do Instituto Benjamin Constant - Rio de Janeiro. Os participantes do estudo foram professores de informática, arte, orientação e mobilidade e educação-física. Para tanto, utilizaram-se do estudo de caso como estratégia e entrevistas como instrumento.

Os resultados apresentam que a principal dificuldade encontrada pelos professores participantes do estudo foi a comunicação, a apontar que a presença de um tradutor e intérprete de Língua Brasileira de Sinais (Libras) é fundamental neste contexto. As ações mencionadas pelos professores foram consideradas relevantes, a possibilitar o acesso de alunos com surdocegueira aos conteúdos das aulas.

Desse modo, é importante os professores conhecerem as características e os desafios enfrentados por surdocegos para comunicar-se e locomover-se, avaliar as repercussões da surdocegueira na vida dos sujeitos, especialmente em relação à comunicação e locomoção. Figueiredo; Chiari; Goulart (2013) discutem sobre esta características e desafíos enfrentados por surdocegos. Para tanto, o estudo contou com a participação de onze surdocegos. Os instrumentos utilizados foram, entrevistas semiestruturadas e questionários, a analizar qualiquantitativamente os dados. As autoras evidenciam que as pessoas com surdocegueira enfrentam situações desafiadoras nas atividades cotidianas, nos relacionamentos pessoais, no trabalho e no lazer. Portanto, é indispensável um olhar diferenciado e reflexivo a essas pessoas, no sentido de dar possibilidades que direcionem para o ganho de independência na linguagem para melhor comunicação, essa é uma ação que se inicia na família e ampliam-se nos espaços escolares.

As ações realizada pelos professores e os planejamentos com boa organização são cruciais para o desenvolvimento dos estudantes com surdocegueira. Nesta perspectiva sobre as ações dos professores, Galvão e Miranda (2013) propõem em seus estudos analisar e discutir as diferentes formas de Atendimento Educacional Especializado - AEE prestado aos estudantes com surdocegueira matriculados na Educação Básica de escolas regulares. A abordagem utilizada no estudo descreve-se como qualitativa, do tipo estudo de caso. Os participantes foram quatro alunos surdocegos. $O$ instrumento de coleta de dados foi uma entrevista realizada com profissionais que atuavam no AEE em escolas de Educação Básica.

Os resultados apresentados indicam ausência de uma ação planejada, gerando improvisação e fragmentação das ações do atendimento educacional especializado e isolamento dos profissionais, a decorrer em ações pedagógicas desarticuladas entre os professores da sala regular e os especialistas. $O$ trabalho entre estes professores devem ser em conjunto a enfatizar o estudante, caso contrário o desenvolvimento dos estudantes se constituirá de modo fragmentado.

Branco e Leal (2018) realizaram em seus estudos uma revisão sistemática, a abordar a inclusão de estudantes surdocegos no ambiente escolar e a atuação dos professores e equipe de profissionais no processo de ensino e aprendizagem desses estudantes. Constatou-se que as ações apresentadas pelos profissionais em relação ao planejamento de atividades são fragmentadas e que esses profissionais necessitam de formação continuada específica para o atendimento de estudantes surdocegos. Entre os profissionais incluem-se, professores de salas de recursos, professor de sala comum e guias-intérpretes. Neste sentido, salienta-se que, a linguagem é um meio de acesso essencial para a comunicação de qualquer pessoa, é o modo que lhes permite ir além das experiências prévias para planejar uma ação futura, portanto são necessárias novas reflexões sobre o atendimento prestado a estudantes com surdocegueira.

A linguagem para Vygostky (1991) é considerada como um instrumento lógico e analítico do pensamento, pois todo desenvolvimento cognitivo se dá por meio da interação social com o outro e com o meio. Com isso, fica 
claro a importância em criar e desenvolver meios de ensino para possibilitar aos estudantes surdocegos à comunicação dos seus pensamentos, sentimentos, sejam eles através de signos gráficos ou gestos.

Andrade (2018) investigou as interfaces entre os campos da surdocegueira e da arte. O estudo contou com a participação de pessoas surdocegas, seus familiares e profissionais do Programa de Atendimento e Apoio ao Surdocego (PAAS), do Instituto Benjamin Constant, Rio de Janeiro. O método utilizado foi da cartografia, a refletir com base na fenomenologia da percepção de Maurice Merleau-Ponty.

Os resultados apontam sobre a relevância da arte para a expressão do ser, para a comunicação, para a ampliação da percepção e para o entendimento de mundo de pessoas surdocegas a partir da arte do bordado e do dialogar, independentemente do tipo de linguagem é utilizada.

De modo geral, a maior parte dos estudos fizeram uso da abordagem qualitativa, com exceção de Figueiredo, Chiari, Goulart (2013) que utilizaram a abordagem qualiquantitativa para analizar e discutir os dados.

Em relação às estratégias, três estudos utilizaram do estudo de caso (Bigatte; Lima, 2019; Almeida, 2017; Galvão; Miranda, 2013). Branco; Leal (2018) utilizaram de revisão sistemática e Andrade (2018) do método de catografia. Araújo et al. (2019), Figueiredo; Chiari; Goulart (2013) não especificaram.

No que concerne aos ambientes e participantes, os estudos foram realizados em ambientes educacionais de ensino, sendo em escolas de educação básica de ensino regular, públicas e privadas, centros de atendimentos especializados em estudantes com surdocegueira, Instituto Benjamin Constant e centros de formação de psicologia aplicada. Os participantes dos estudos foram estudantes com surdocegueira, familias de estudantes com surdocegueira, professores de ensino regular inclusivo, guías-intérpretes e professores de centros especializados.

No que diz respeito aos instrumentos adotados para a coleta dos dados, os estudos valem-se de entrevistas (Araújo et al., 2019; Bigatte; lima, 2019; Andrade, 2018; Almeida, 2017; Figueiredo; Chiari; Goulart, 2013; Galvão; Miranda, 2013), questionário (Araújo et al., 2019; Figueiredo; Chiari; Goulart, 2013) e observação (Araújo et al., 2019). Verficou-se que alguns dos estudos utilizaram de mais de um instrumento para análise. Especificamente, apenas um estudo abordou bases de dados como instrumento (Branco; Leal, 2018).

Em suma, os estudos apresentam na sua maioria, apontamentos sobre o processo de comunicação a estudantes com surdocegueira. Todavia o cenário educacional necessita de estudos que abordem práticas pedagógicas que direcionem novas formas de aprendizagem para comunicação e a alfabetização de estudantes com surdocegueira, a considerar a educação em um perspectiva inclusiva. Em relação a alfabetização, os estudos apresentam carências de produções científicas voltadas para as áreas de comunicação e alfabetização de estudantes com surdocegueira.

Frente aos estudos localizados e selecionados, não foram encontrados estudos que tratem específicamente sobre o processo de alfabetização de estudantes com surdocegueira, e sim, a apresentação de algumas formas para o processo de alfabetização, como recursos e/ou tecnologias acessíveis.

\section{Conclusões}

Este estudo buscou investigar o que apresentam os estudos sobre comunicação e alfabetização de estudantes com surdocegueira. Para tanto, utilizou-se da base de dados do Portal de Periódicos CAPES/MEC/BRASIL, a constatar dados entre o período de 2008 a 2020.

Verificou-se a partir dos estudos selecionados (Araújo et al., 2019; Bigatte; Lima, 2019; Andrade, 2018; Branco; Leal, 2018; Almeida, 2017; Figueiredo; chiari; Goulart, 2013; Galvão; Miranda, 2013) que apesar dos estudos 
apresentar posibilidades para a comunicação e alfabetização de estudantes com surdocegueira, ainda há necessidade de novas propostas, a considerar o aumento significativo de estudantes com essa deficiência em salas de aula inclusiva e a falta de qualificação de profissionais habilitados para atendê-los.

A maioria dos estudos selecionados apresentam apontamentos sobre o processo de comunicação e alfabetização a estudantes com surdocegueira, mas, não mostram práticas pedagógicas que podem ser utilizadas durante o processo de aprendizagem a ser aplicadas para a comunicação e alfabetização de destes estudantes, e sim, recursos e tecnologias acessíveis e disponíveis.

À vista disso, compreende-se que há necessidade de estudos que abordem práticas pedagógicas que possam auxiliar professores que trabalham com o ensino inclusivo de estudantes com surdocegueira, profissionais da área da educação especial, com objetivo de promover metodologias e didáticas que possam levar a aprendizagem da comunicação e alfabetização destes estudantes, a disseminar uma educação mais inclusiva.

\section{Referências bibliográficas}

Brasil. (1996). Congresso Federal. Lei. 9.394. Lei de Diretrizes e Bases da Educação Nacional. Publicado no D.O.U. Estabelece as Diretrizes e Bases da Educação Nacional. Recuperado de http://portal.mec.gov.br/index.php?option=com_content\&view=article\&id=12907:legisl acoes\&catid=70:legislacoes. Acesso em: 15 jan. 2020.

. (2015). Estatuto da pessoa com deficiência. Legislação Brasileira de Inclusão da pessoa com deficiência. Recuperado de http://www.planalto.gov.br/ccivil_03/_ato20152018/2015/lei//13146.htm. Acesso em 19 ago. 2020.

. (2006). Ministério da Educação e da Cultura. Saberes e Práticas da Inclusão. Dificuldades de comunicação e sinalização: Surdocegueira / múltipla deficiência sensorial. Secretaria de Educação Especial - Brasília: MEC/SEESP. Recuperado de http://portal.mec.gov.br/seesp/arquivos/pdf/surdosegueira.pdf. Acesso em: 04 mar. 2020.

. (2012). Portaria № 867, de 4 de julho de 2012. Institui o Pacto Nacional pela Alfabetização na Idade Certa e as ações do Pacto e define suas diretrizes gerais. Diário Oficial da União, 5 jul. Recuperado de http://www.pacto.proex.ufu.br/documentos. Acesso em: 10 abr. 2020.

. (2008). Política Nacional de Educação Especial na Perspectiva da Educação Inclusiva. Recuperado de http://portal.mec.gov.br/arquivos/pdf/politicaeducespecial.pdf. Acesso em: 12 jan. 2020.

Bakhtin, M. V. (1997). Estética da criação verbal. Trad. Maria Ermantina Galvão G. Pereira. São Paulo: Martins Fontes.

Costa, M. da P. R. da; Cader-Nascimento, F. A. A. (2003). Mediação pedagógica no processo de desenvolvimento da comunicação em crianças surdocegas. Temas em Psicologia, Ribeirão Preto, v. 2, p. 85-96. Recuperado de http://pepsic.bvsalud.org/scielo.php?script=sci_arttext\&pid=S1413389X2003000200002. Acesso em: 03 mar. 2020.

Declaração Universal dos Direitos Humanos. (1948). Recuperado de http://www.mp.go.gov.br/portalweb/hp/7/docs/declaracao_universal_dos_direitos_do_homem.pdf>. Acesso em: 5 mar. 2020.

Flick, U. (2009). Introdução à pesquisa qualitativa. 3 ed. Porto Alegre: Artmed. 
Frangella. R de C. P. (2016). Políticas de formação do alfabetizador e produção de políticas curriculares:

pactuando sentidos para formação, alfabetização e currículo. Práxis Educativa, Ponta Grossa, v. 11, n. 1, p. 107-128, jan./abr. Recuperado de

https://www.researchgate.net/publication/284517664_Politicas_de_formacao_do_alfabetizador_e_prod ucao_de_politicas_curriculares_pactuando_sentidos_para_formacao_alfabetizacao_e_curriculo. Acesso em: 15 jan. 2020.

Giacomini, L.; Maia, S. R. (2005). O atendimento ao aluno surdo-cego. In: Mendes, E. G; Almeida, M. A; William, L. C. de A. (Orgs.). Temas em Educação Especial: avanços recentes. São Carlos: EduUFSCar.

Gomes, R. M; Nunes, P. O.R. L. (2013). Estudo descritivo das interações de professores em formação inicial e alunos com surdocegueira. Recuperado de https://periodicos.fclar.unesp.br/iberoamericana/article/view/6478. Acesso em: 25 jan. 2020.

Sampaio, R. F.; Mancini, M. C. (2007). Estudos de revisão sistemática: um guia para síntese criteriosa da evidência científica. Revista Brasileira de Fisioterapia, São Carlos, v. 11, n. 1, p. 83-89. Recuperado de https://www.scielo.br/scielo.php?script=sci_arttext\&pid=S1413-35552007000100013. Acesso em: 20 jan. 2020.

Soares, M. (1998). Letramento: um tema em três gêneros. Belo Horizonte, MG: CEALE.

Souza, J. C; Filho, N. J. (2017). Entre a escuridão e o silêncio: a relação entre as Tics e a surdocegueira utilizando a ferramenta do código morse. Rev. online de Política e Gestão Educacional, v. 21, n. esp. 1, p. 881-895. Recuperado de https://periodicos.fclar.unesp.br/rpge/article/view/10458/6816. Acesso em: 11 jan. 2020.

Vygotsky, L. S. (1997). Fundamentos de defectologia. Obras Escogidas V. Moscú: Editorial Pedagógica. (1991). Pensamento e Linguagem. 3 ed. São Paulo: Martins Fontes.

Watanabe, D. R., Giacomini, L., \& Maia, S. R. (Org.). (2006). Entrando em contato com as pessoas surdocegas: Formas de comunicação (Vol. 2). São Paulo: Grupo Brasil.

Watanabe, D. R., \&; Maia, S. R. (Org.). (2012). Projeto pontes e travessias: Formação de guia-intérprete. São Paulo: Ahimsa.

Esta obra está bajo una Licencia Creative Commons Attribución-NoCommercial 4.0 International

\section{(cc) $\overline{\text { EY-NC }}$}

